\title{
Right-Side Sleeping Position Prevents Sudden Infant Death Syndrome a Literature Review
}

\section{Othman Alfleesy ${ }^{*}$}

Associate Professor of Forensic Medicine, Department of Forensic Medicine and Pathology, Faculty of Medicine and Health Sciences, Aden University, Aden, Yemen

${ }^{*}$ Corresponding author: Othman Alfleesy, Associate Professor of Forensic Medicine, Department of Forensic Medicine and Pathology, Faculty of Medicine and Health Sciences, Aden University, Aden, Yemen, Tel: 00967 770548026, E-mail: alfleesy2001@yahoo.com

Citation: Othman Alfleesy (2016) Right-Side Sleeping Position Prevents Sudden Infant Death Syndrome a Literature Review. J Forensic Sci Criminol 4(2): 204

Received Date: March 09, 2016 Accepted Date: April 27, 2016 Published Date: April 28, 2016

\begin{abstract}
Background: Studies showed that sudden infant death syndrome (SIDS) has association with sleeping positions. Up-to-date no study explained how could they prevent it.

Objectives:

- To determine which sleeping position is certainly safe one to prevent SIDS.

- To establish criteria for suggesting definition and making diagnosis for SIDS.

- To discuss the controversy surrounding, ALTE, as compared to SIDS.

Method: This literature review was built on a previous literature. Articles were obtained randomly according to their availability to the author. For the purpose of this work an easy approach was built by modeling an overview on SIDS topic after clarifying the misconception and misinterpretation of a number of controversial issues in regard to SIDS such as: Asphyxia, Apparent Life Threatening Event (ALTE), and comparing the findings with the literature review results. By this unique method we got a clue for prevention of Sudden Infant Death Syndrome.

Results: The revision revealed with no doubt that no study before have studied right-side sleeping position at all. The author determined right side as the only safe position to preventing SIDS. A new definition for SIDS is suggested. The author postulated a Right side position hypothesis (Alfleesy hypothesis) which is a testable hypothesis in front of all researchers for further study.

Conclusion: Our results contradict totally all previous studies and recommendations. We recommended strongly the right side position only for sleeping to prevent SIDS. New definition is suggested and a new hypothesis is postulated.

Keywords: Right-side sleeping position; Sudden infant death syndrome (SIDS); Apparent life threatening event (ALTE); Asphyxia

List of abbreviations: SIDS: Sudden infant death syndrome; ALTE: Apparent life threatening event
\end{abstract}

\section{Introduction}

For nearly 3000 years, it has been recognized that apparently healthy infants could die suddenly and unexpectedly usually during sleep [1]. After that, this phenomenon got its name as sudden infant death syndrome. SIDS is a common cause of infant's deaths in developing countries. It affects about one out of every 500-600 live births. This accounts-in 80s- for 6000 to 10000 deaths in the U.S per year [1,2]. Athanasakis E, et al. stated: moreover, SIDS is classified by Centre of disease control (CDC) as the third leading cause of overall infant mortality in USA [3]. The three leading causes of infant death are: congenital malformation,

Low birth weight and SIDS taken together accounted for $45 \%$ all infant deaths [4].

SIDS (cot death) was the prime problem in front of researchers all over the world- that could not be prevented - and still with unknown etiology [5]. It is the most common cause of death between the ages 1 week - 2 years, the number increases during the first year $[1,2,6]$. This study is based upon previous studies of the author presented at the Meeting of International Academy of Legal Medicine and Social Science that was held in Genoa, Italy [7]. The controversial issue relevant to this study is: autopsy findings in asphyxia, SIDS, and ALTE. These issues have provided some early data and formed the base for this current study and used for comparison to the new results. The data of the study were collected from a huge number of researches and articles published in scientific journals and data base searching. My study into the problem of SIDS over the past 24 years has revealed what the author concluded to be the solution for SIDS. 
The current study gains its importance because it gives -for the first time- a solution to preventing SIDS, which have been never suggested before. This work determines the only safe sleeping position to prevent SIDS, and mentions the other causal risk factors. These outcomes resulted after having a clear ideas and concepts about those topics in the circle of controversy. By reviewing the literature, this revision seems to be relatively the only one since the beginning of studying this phenomenon has discussed different topics and issues and forwarded them in this study. The author discovered why the thinking about SIDS lacked the logical and approach it deserved. Numerous studies, flooding of theories, hypotheses, causes and factors were gushed, and Billions of Dollars and Pounds were put as FUNDS for supplying these researches, and the result was: SIDS still with unknown etiology. The importance of obtained results by this study lies into that it guarantees and calms the parents and different world associations to prevent SIDS to their infants by the recommended advices. Finally the author postulates his hypothesis, suggesting new definition for SIDS and open doors for future studies. It does not seem surprising that there were a confusion, unclear concepts, illogic suggestions and ideas for decades to study this problem.

\section{Background}

\section{What is known about SIDS?}

SIDS (cot death) has been recognized since Biblical times, the first reported case being in old testament (I King, ch.3.v.19 ) [6]. Many more children die of SIDS in a year than all who die of cancer, heart diseases, pneumonia, child abuse, AIDS. SIDS accounts for 1000 deaths each year in Canada and 1500 deaths a year in Britain (Calwell, 1995).

Flooding of researches discussed all aspects of SIDS with no results as follows:

Definition of SIDS: In 1963 the term (crib death) was changed to SIDS. In 1969, the Second International Conference on Sudden Infant Death gave the following definition: every sudden, unexpected death of an infant where post mortem Investigations don't explain death [8]. It was universally accepted. Despite slight changes suggested in 1989 (clinical history and scene of investigation), SIDS remains a diagnosis of exclusion $[1,2,5,9,10]$.

The clinical history and manifestations: were summarized as follows: a child within the age of two years, in a good heath, without previous disease, put in a bed, and is either found dead in its sleeping place in the early morning, or is found dead some hours, after its early feed $[1,2,11]$. The infants suffered from cyanosis, apnea, frightening, choking and others.

Autopsy Findings: In spite of all the efforts expended; the pathologists established the diagnosis of SIDS by exclusion only. During their autopsy the pathologists found that the pathological features of SIDS as follows: intrathoracic petechiae (on thymus, heart, lungs, parietal pleura, pericardium, and diaphragmatic pleura). Pulmonary edema, frothy fluid, all these features are suggestive, but nor diagnostic, of SIDS $[1,2,5,11,12]$.

Theories: Although theories exist as to factors contributing to SIDS, the cause of SIDS deaths is still, by definition, unexplained [13]. Some of these theories were as follows: Overlying, hypothermia, parathyroid insufficiency, $\mathrm{Co}_{2}$ toxicity, allergy to cow's milk, heavy bed clothes, sleep apnea syndrome, arousal mechanisms, cardiac arrhythmias, chronic asphyxia, hypoxia, blocked air passages. All theories failed to explain SIDS; because they could not know how it is occurring? Many causes of SIDS have been postulated and have either remained unconfirmed or have been disproved [1]. Finally they said: SIDS remains a mystery [1,6].

Sleeping Position [1,2,14,15,16]: Since 1985, investigators from around the world focused on sleep positions and no definite answer was found even after the sorrow recommendations of the American Academy of Pediatrics (AAP) which led to more deaths. They found that there is an association between sleep positions (mainly prone, also supine, and side) and SIDS. But they could not determine which position is the cause of SIDS or which one is the safe position?

Causes, Risk factors: Identified in the studies of SIDS infants were : age (more in the first year), sex (more in males), seasons (more in winter), race, social class, prematurity,twins, time of death (more at night), all sleeping positions but mainly prone position, maternal smoking during pregnancy), bottle feeding, young maternal age, low birth weight, temperature and others [17,18]. Alexander et al stated: Much is known about risk factors for SIDS, however the true cause (or causes) of SIDS are still largely unexplained [13].

Until today no uniform explanation exists, Some exclusively remark upon obstructive asphyxia [19], and refer to typical signs of asphyxiation which be found very often [1]. Other favor reflex mostly vagal inhibition of the heart but without explanation. Others restricted their theories to apnea without determining the specific cause. There were no diagnostic criteria for SIDS and there was no accurate method for prospective study too.

\section{Objectives}

1. To determine which sleeping position is certainly safe one to prevent SIDS.

2. To establish criteria for suggesting definition and making diagnosis for SIDS.

3. To discuss the controversy surrounding ALTE as compared to SIDS. 


\section{Materials and Methods}

My study was based on a literature review of previous studies. Researches were studied after gaining from scientific journal, books, searching electronic database, proceedings, titles, abstracts. The results were used by the author for comparisons. The author found a gap in the knowledge and the review generated a significant and an important knowledge used for bridging the link for all previous studies. This failure to understanding the nature of both SIDS and ALTE was located in misunderstanding and misinterpretation of the controversial topics in concern, which were absent in all studies. The literature review evaluated the studies and derived an overview in different controversial topics. The data were extracted, reviewed and interpreted for study purpose and for comparison with regard to the following parameters:

1) Definitions of SIDS (2) Clinical manifestations of SIDS \& ALTE (3) Sleeping positions (4) Autopsy findings. (5) Controversial issues in relation (ALTE).

\section{Results}

Also the results explained that prone (front), supine position was recommended by many researchers and associations, for instance the American Academy of Pediatrics (AAP). Also the results point out that no one before had mentioned or discussed the right side sleeping position alone at all in his studies, and no one had recommended it before (Table 1).

\begin{tabular}{|c|c|}
\hline $\begin{array}{c}\text { Which sleeping position - the investigators found- has an } \\
\text { association with SIDS? }\end{array}$ & All sleeping positions (mainly prone) \\
\hline $\begin{array}{c}\text { Is there any study in the review of the literature titled Rt. sleeping } \\
\text { position as a safe one? }\end{array}$ & No study, no research, no article, no paper at all. \\
\hline $\begin{array}{c}\text { Are there any researcher had } \\
\text { Studied Right side sleeping position or recommended it? }\end{array}$ & No researchers, no associations. \\
\hline Did they determine definitely any safe position? & No safe sleep position was determined \\
\hline Did they determine definitely one position only as a risk position? & No sleep position was determined with certainty \\
\hline $\begin{array}{c}\text { Is there any study had tested the hypothesis of Rt side sleeping } \\
\text { position before? }\end{array}$ & No any study. \\
\hline
\end{tabular}

Table 1: Shows studies which mentioned that sleeping positions have associations with SIDS. No investigator before either studied or recommended Right side sleeping position

The current definition (which considered by the author as old one) stated: every sudden unexpected death of an infant where postmortem investigations do not explain death [8]. The terms with their concepts which considered as a standard for this definition were:

- Sudden: Happening, coming, or done quickly and unexpectedly [20].

- Infant: This is the period of age up to two years.

- Death during sleep: This relates to sleep only.

- Autopsy findings: They said (of no significance).

It is clear that in this definition, we find no criteria for diagnosis. The definition itself is lacking the most important features, characteristics, for diagnosis and for its application in practice (Table 2).

\begin{tabular}{|c|c|c|c|c|}
\hline Sudden $^{1}$ & Infant & Death & Sleep $^{\mathbf{2}}$ & Autopsy $^{\mathbf{3}}$ \\
\hline $\begin{array}{c}\text { It does not define a time } \\
\text { perfectly (loose term) }\end{array}$ & Infant & Death & $\begin{array}{c}\text { It does not define } \\
\text { the position }\end{array}$ & $\begin{array}{c}\text { Of no } \\
\text { significance. }^{3}\end{array}$ \\
\hline
\end{tabular}

1,2,3, All these words are unusual for diagnosis. If the autopsy: of no significance, the author asks: If the autopsy of no significance why do you perform an autopsy? This is called a mutilated autopsy Table 2: Shows the terms (words) included in SIDS definition. The definition of SIDS lacks precision and clarity in a number of areas. No risk factors no criteria exists for diagnosis and definition

All these findings are signs of asphyxia (Table 3).

\begin{tabular}{|c|c|c|c|c|}
\hline \multirow{2}{*}{ Phenomenon } & \multicolumn{4}{|c|}{ Autopsy findings } \\
\cline { 2 - 5 } & $\begin{array}{c}\text { (I.T.H.) })^{1} \text { Petechial } \\
\text { hemorrhages }\end{array}$ & $\begin{array}{c}\text { Pulmonary } \\
\text { edema }\end{array}$ & $\begin{array}{c}\text { Food in } \\
\text { Stomach }\end{array}$ & $\begin{array}{c}\text { Food, frothy } \\
\text { fluid in air } \\
\text { passages }\end{array}$ \\
\hline SIDS & Found & Found & Found & Found \\
\hline
\end{tabular}

'The petechial hemorrhage's were found in the thoracic organs: (lungs, thymus, and heart)

Table 3: Autopsy findings in SIDS 
It is clear that these phenomena are similar in all manifestations, except death and autopsy findings (SIDS) that is why they have said: SIDS is a continuous ALTE (death) and ALTE is escaped SIDS, or interrupted SIDS (alive) (Table 4, 5 and 6).

\begin{tabular}{|c|c|}
\hline \multicolumn{2}{|c|}{ Clinical manifestation of SIDS } \\
\hline Cyanosis & present \\
\hline Apnea & present \\
\hline No breast feeding(bottle or semisolid) & Yes \\
\hline $\begin{array}{c}\text { Non Right-side sleeping position(mainly } \\
\text { prone) }\end{array}$ & Yes \\
\hline Death during sleep & Occurs \\
\hline Limbness & Yes \\
\hline Obstructive asphyxia & suffers \\
\hline Agonizing & suffers \\
\hline Choking & suffers \\
\hline${ }^{1}$ Frightening (by witness) & Yes \\
\hline Autopsy findings & Signs of asphyxia \\
\hline
\end{tabular}

${ }^{1}$ Some said rarely

Table 4: Shows clinical manifestations and findings of SIDS

\begin{tabular}{|c|c|}
\hline \multicolumn{2}{|c|}{ Clinical Manifestations of ALTE } \\
\hline Non Rt side sleep position(mainly prone) & Yes \\
\hline $\begin{array}{c}\text { No breast feeding(bottle or semisolid } \\
\text { food) }\end{array}$ & Yes \\
\hline Cyanosis & Present \\
\hline Apnea & Suffers \\
\hline Death during sleep & Escaped \\
\hline Limbness & Present \\
\hline Obstructive asphyxia & Present \\
\hline Frightening & Watched \\
\hline Choking & Found \\
\hline Agonizing & Suffers \\
\hline Autopsy findings(dead infant) & Escaped(alive $)^{1}$ \\
\hline
\end{tabular}

${ }^{1}$ These phenomena are transit either to death (SIDS), or escaping death (ALTE) Table 5: Clinical manifestations, risk factors which were found in ALTE

\begin{tabular}{|c|c|c|c|}
\hline \multicolumn{2}{|c|}{ Phenomenon } & SIDS & ALTE \\
\hline \multirow{10}{*}{$\begin{array}{l}\text { Clinical } \\
\text { findings }\end{array}$} & Cyanosis & Present & present \\
\hline & Frightening & Watched ${ }^{1}$ & watched \\
\hline & Apnea & Suffers & Suffers \\
\hline & Limbness & Present & present \\
\hline & Frothy fluid & Present & Present $^{2}$ \\
\hline & $\begin{array}{c}\text { Obstructive } \\
\text { asphyxia }\end{array}$ & Suffers & Suffers \\
\hline & Agonizing & Suffers & Suffers \\
\hline & Death during sleep & Occurs & $\begin{array}{c}\text { Escaped } \\
\text { death(alive) }\end{array}$ \\
\hline & Choking & Suffers & Suffers \\
\hline & $\begin{array}{c}\text { (Signs of asphyxia) } \\
\text { Autopsy findings }\end{array}$ & $\begin{array}{l}\text { Found (Death } \\
\text { case) }\end{array}$ & $\begin{array}{l}\text { Escaped death(a } \\
\text { live infant) }\end{array}$ \\
\hline
\end{tabular}

${ }^{1,2} \mathrm{At}$ the time of the death, the infant is rarely being watched

Table 6: in which the following clinical manifestations and findings were found and represents the similarities in both disorders (SIDS and ALTE) for an infant 


\section{Discussion}

During studying the author discovered that there is a gap found in all studies and researches due to inadequate knowledge which led to misinterpretation and unconvincing opinions. Also no studies are known to have examined the Rt-side sleeping position.

A link between ALTE and SIDS has been noted in much of the literature, but due to misinterpretation of the nature of these entities the researchers failed to answer. The researchers have not delineated the differences between SIDS and ALTE infants.

My study provides an opportunity to examine the link between all controversial issues particularly SIDS and ALTE. Goldwater stated: This review will explore in detail the arguments that abounded the time and discover why the thinking about SIDS lacked the logical and considered approach it deserved [21].

The author determined the risk factors which act as a trigger agents leading to the events. The most important finding of this present study is that it reveals and explains the contradicting results present in the previous studies of researchers which also contradict the results of this study, as for example in sleep positions. Also by this study new results and knowledge supported the author to put forward his hypothesis and to call all investigators to study again this phenomenon on this new scientific basis. All articles point to the prone or lateral position during sleep as risk factors [13,22]. This study may offer evidence for investigator as to the physiological changes associated with Rt- side position to be the safe sleeping position and may open the door for future studies.

\section{Definitions $[23,24]$}

On sudden infant death, the precedent researchers never proposed a comprehensive definition for SIDS. With the inadequate knowledge of the previous studies one could not catch any information for solving or defining SIDS. because they all rotate in the same vicious circle lacking a clear concepts. Steinshneider wrote: There is a number of researchers, who have suggested the discussion of the SIDS' definition for the purpose to change it or suggested a new unsuccessful definition [25].

Thus the author presents an overview contributing a solution for this problem.

By reviewing the history of the SIDS definitions since the first (conventional definition) of the second international conference on SIDS held in 1969 the following definition stated:

1 - Every sudden, unexpected death of an infant where postmortem investigations do not explain death [2,5]. And it is universally accepted up to date. Some of researchers commented about this definition: In their view about this definition an autopsy though is mandatory for the diagnosis but leads to uncertain results [11]. Because the diagnosis of SIDS was based on a loose definition which itself was valueless.

2- The sudden death of an infant under one year of age that remains unexplained after a thorough case investigation, including performance of a complex autopsy, examination of the death scene and a review of the clinical history [26].

The definitions of SIDS were revised and some of the scientists discussed the word sudden, as is it necessary to be found in the definition or not? [27].

In general, all definitions were including the following terms only:

1-The infant - some restricted to one year, others said: two, others said: child.

2- Healthy, some added upper respiratory tract infection.

3-Death occurs during sleep.

4- Postmortem examination reveals no thing (autopsy findings of no significance).

The main problem accompanied all studies of SIDS was the absence of a definite criteria for the researchers to base their researches in concern with SIDS accordingly in order to have a correct definition and a right approach for diagnosis.

JB. Beckwith stated: SIDS lacks adequate definitional criteria [10].

Beside this, most of the researchers in the last decade started to have some proposal for SIDS definition which emphasized the existence of confusion of such definitions too. Dr. P. J. Rintahaka said: "In point of fact, the very heart of that definition is the ignorance of the pathologist, his inability to explain the death nothing more, nothing less" [8]. With a view to the defects of these definitions and after a review of the history of SIDS definitions.

It is well-known on the basis of medicine -in the daily practice- that if you want to diagnose a disease it is necessary to have its signs and symptoms, or to diagnose a problem it is necessary to know its elements. And this was not found in the SIDS definitions. So how SIDS could be defined with such situation? To evaluate the proposed criteria for both definition and diagnosis according to the results of this work, it is necessary to compare the components of the current definition of the investigators and the author's definition. 
The terms (words) of the current definition for SIDS not clinically useful or meaningful for both definition and diagnosis [Table 7].

\begin{tabular}{|c|c|c|}
\hline Terms (words) & Current definition & Alfleesy definition \\
\hline Sudden & Mentioned & Dropped \\
\hline Age & Infant & Infant \\
\hline Death during sleep & Mentioned & $\begin{array}{c}\text { Non-Right side sleeping } \\
\text { position (mainly prone) }\end{array}$ \\
\hline Sleeping position & No position \\
mentioned & Not mentioned & Mentioned \\
\hline $\begin{array}{c}\text { No breast feeding(bottle } \\
\text { or semisolid) }\end{array}$ & Of no significance & $\begin{array}{c}\text { Show signs of asphyxia, and } \\
\text { stomach must contain food }\end{array}$ \\
\hline Autopsy findings
\end{tabular}

Table 7: Shows the differences in the components of words and terms for Alfleesy and current definition for SIDS

Table 7 provides the comparison of a definition (in current use) and new one (alfleesy definition). It is clear that the old one has the repetition of the term (sudden) almost in all definitions. The old definition had not mentioned: (a) the sleeping position (b) Ingesting food (meal) before sleeping. (C) It did not emphasize on the presence of asphyxial signs after the autopsy and presence of food in stomach. The new definition dropped out the term (sudden), as death does not occur immediately, but due to obstructive, mechanical asphyxia and its consequences which is a process. The time of this process (agony) is either long or short depending up on a number of factors. On the ground of previous discussion and results of this study the following criteria are taken into consideration while making the suggested new definition.

1- The word (sudden) was dropped, because there was no standardization for the term "sudden". It is necessary to put this term (sudden) in the language of time period: minutes, hours. The period of "sudden death" by WHO is 24 hours, but according to the author view it is not so and could not be applied to "sudden infant death syndrome" [27]. Probably that period (24 hours) is restricted to deaths resulted from diseases as for instance CCF. In other words the term "sudden" included in the English language dictionaries means: anything that occurs quickly, unexpectedly, immediately [20]. But the death in infant by that mechanism of death needs "hours" not seconds or day. The investigators stated in clinical manifestations of SIDS (Found after some hours after sleeping) $[1,5,8]$ and this is consistent with the opinion of the author.

2-The death occurs during sleep.

3-The death may occur to healthy infant

It is necessary to note that even in restricting the definition to "healthy" infants, but this does not exclude the possibility of finding some abnormalities during autopsy.

4- Sleeping must be on non-Right side positions (prone, supine and left side positions) that are associated with SIDS, the Right side position being the only safe one.

5- Full stomach no breast feeding i. e bottle feeding or artificial feeding semisolid food [22,28].

6- Postmortem examinations shows the signs of mechanical obstructive asphyxia and stomach must contain food.

As a result of forgoing discussion the author wishes to suggest his standardized new definition for infant death during sleep (sleeping death).

It is a death, which may occur to an infant, during sleeping, after feeding, and lying down (or be placed ) on non-Right side position (mainly prone), and the postmortem examination shows signs of mechanical obstructive asphyxia only and the stomach must contain food.

\section{What are the scientific data in concern to this discussion?}

\section{The Pathological Changes}

Initially researches on SIDS were centered around the performance of an autopsy [1]. After along time of investigations and practice on SIDS cases, now, it is well known to forensic pathologist the whole autopsy findings. In fact the autopsy findings are present in different cases either natural or unnatural death as in CCF or smothering. The presence or absence of one or two signs of findings never excludes the occurrence of death by asphyxia. Pathologists established the diagnosis of SIDS by exclusion when they are unable to identify other specific causes for infant's death [10]. The pathologic features of SIDS are the autopsy findings of intra thoracic petechiae (on thymus, heart, lungs, parietal pleura, pericardium, and diaphragmatic pleura), frothy fluid coming out from the mouth, gastric contents in the air passages, pulmonary edema.

Knight wrote: “... Certain features are common to most forms of asphyxia; though they may be minimal or absent in many cases ... the multiple small hemorrhages are the most significant features [28]. 
Alfleesy concluded in his paper (Asphyxia for all) [7]. "All these signs might be present or absent in natural or unnatural deaths. They could be found in deaths due to hanging, congestive cardiac failure, sudden infant death syndrome, and others.

Whatever the cause of death; asphyxia is present, regardless of appearance, presence or absence of these signs, as it is (Asphyxia for all). Autopsy cannot distinguish death by SIDS from death by suffocation [1]. This statement by Keens indicated the confusion of researchers in concern with asphyxial process.

\section{Apparent Life - Threatening Event (ALTE) [29,30]}

ALTE is a well-known event to the researchers without explanation. It replaced misleading terms, such as "near-miss SIDS" or "aborted crib death" which implied a direct association between these symptoms and SIDS [31]. However, debate exists as to whether ALTEs are interrupted SIDS events, a separate phenomenon, or an event related to SIDS [30,32,33]. The researchers studied it thoroughly in association with SIDS, but still the underlying aetiology of both was not understood. The term ALTE was coined by the 1986 national institutes of health consensus development conference on infantile apnea and home monitoring.

ALTE is defined as an episode that is frightening to the observer and that is characterized by some combination of apnea, color changes (cyanotic), marked change in muscle tone (limbness) [31]. The researchers admitted that the Survivors of an ALTE share many risk factors for SIDS. The researchers declared their confusion in concern to ALTE. The author believes that this confusion is an extension of the SIDS misconception, misinterpretation raised from no standardization of its definitions.

The failure to link between ALTE and SIDS was due to impatience for observers or caregiver to stay beside the infants hours watching their changes.

The other factor which participated in this unsuccessful result is the way of researchers in studying SIDS AND ALTE. The researchers were imitating each other with some terminological changes but them still running around the same circle.

ALTE is a process of dying which might have or have not ended with SIDS. SIDS and ALTE are in the same line with two consequent stations. SIDS is the end result of some ALTE infants. Some infants are found agonizing and die before any help can be obtained.

Vigorous stimulation is the only way which might revive the ALTE infant -in time- when the observer observed the infant in the process of asphyxia or dying process. A number of physicians and non-physicians are convinced that timely intervention has affected the recovery of some infant. The frightening symptom is the silent shouting of the infant saying: "I am going on to die". SIDS and ALTE share the same risk factors, the same clinical findings (before death) and SIDS has autopsy findings (death). They are not two entities. SIDS is the next and final station on the same road line preceded by ALTE which (ALTE) if not stopped (a timely interference) might end to death (SIDS).Actually, It is impossible to select infants for studying and put them in two groups, categories, etc., as most pediatric centers researchers do, one group for ALTE, the other for SIDS. This is not logic as there are no infants carrying marks indicating these two events or phenomena. Also there are no racial differences. The researchers put classification far away from clinical ground.

An association between SIDS and ALTE was suggested because of prior ALTE events in 5\% of SIDS victims [33]. The investigators declared their confusion in concern to ALTE.

The case definition in ALTE depends upon parental observations, which have been shown to be unreliable in several studies [30]. There are clinical similarities between SIDS and ALTE, the only difference is that in SIDS the death had occurred while in ALTE the infant escaped from death. From this information it is clear that SIDS is a continuity of ALTE till death and ALTE is interrupted SIDS. It is a transit either to death or to escaping from death.

\section{The process of death or escaping death}

Infant: Non right side sleeping position (mainly prone) + full stomach $\rightarrow$ clinical findings + frightening (represents beginning of asphyxia or dying process) + stopped by a timely mechanical intervening $\rightarrow$ ALTE.

The same Infant: Non right side position (mainly prone) + full stomach $\rightarrow$ clinical Findings + frightening (represents beginning of asphyxia or dying process) -no mechanical intervening in time $\rightarrow$ SIDS.

\section{Sleeping Position [15,16,32,34,35]}

Initially, researches on SIDS centered on the performance of an autopsy upon the infants. But, since 1985 investigators from around the world focused on sleep positions $[1,2,10]$.

An infant's sleep position has been identified as a major risk factor for SIDS. Prone (belly) sleeping position is known to associate with an increased risk for SIDS [36-38]. In 1992 the American Academy of Pediatrics recommended placing infants to sleep in the non-prone (back or side) position $[39,40]$. In spite of that some researchers stated: In addition to the increased risk of SIDS for infants sleeping in the prone position, an increased risk has also been found to be associated with side sleeping position [38].

But After this recommendation of The American Academy of Pediatrics, there was a decline in statistical number of deaths. MF MacDorman, et al. 2014, stated that, in 2010 the infant mortality rate was 6.1 infant deaths per 1000 live births. And in 2011 infant mortality rate 6.07 infant deaths per 1000 live births [41]. 
Recently in the USA most researchers are dealing with the study of the prone sleeping position as this position is the prevalent one later on they recommended mothers to change their infants position to other positions and the problem still found [39,40,42].

There is a consensus about the association between SIDS and the sleeping positions (mainly prone, supine) [1,28,34,43-45].

Many recommendations were made but with no difference, and they could not determine which one of the other sleeping positions is the safe one? There is no evidence that SIDS can be entirely prevented at present [1]. Supine or side sleeping position will not eliminate SIDS, infants have died in all sleep positions including back and sides [1].

Edwin mitchill stated: recent evidence suggests that sleeping on the side doubles the risk of SIDS compared with sleeping in supine position $[35,46,47]$.

This contradicts with the statement of other researcher who declared: No data proving or even strongly suggesting that sleeping in the lateral or supine position is harmful to healthy infant. Other still insists on the prone position: there are still good reason for placing certain infant's prone [48].

All scientists tried to find the cause of SIDS in sleeping position but with uncertainty. The prone / supine sleeping positions have been found to be associated with an increasing of airflow resistance, lowering the arousal threshold and the possibility of mechanical occlusion of the upper respiratory passage $[1,5,49]$.

This study reveals that no one studied the Right side sleeping position, mentioned it or recommended it. No study determined that Rt side position is a safe posture at all.

One of the investigators declared: we did not evaluate the effect of sleeping on the side [42]. As already noted, the association between the prone, supine sleeping position and the risk of sudden infant death syndrome (SIDS) has been found in almost all studies in which it has been sought. All studies, with no exception showed positive association between prone, supine, side positions and SIDS but with different percentages, and no study determined one safe position. The main questions which raised frequently, or which must be answered:

Which sleep position is the safe one, and which sleep position is a causal for SIDS? Also what are the risk factors and protective factors for SIDS and ALTE?

Sleep positions for infants are different in different countries. Asian parents putting their infants to sleep on their backs [50]. In other countries either related to tradition (habits) or to religion instructions, as for example in Islamic countries in which the prone position is prohibited, as it is included in our Sunna (the instruction of our Prophet Mohamed - BPUH) informed us that "the prone (front) position is prohibited and the right side position is advised to be the side of sleeping" [51]. Our prophet advocated right side sleeping position. Also Allah the god in the holy quran mentioned breast feeding. Allah says: "Mothers shall suckle their children two years completely for such as desire to fulfill the suckling" [52].

So, the causal factor (risk factor) is prone. The protective factor is breast feeding [53]. But this didn't mean that some mothers put their infants in back position but most of them feed them with breast milk [53]. I think that this is the case, why in Arabic countries SIDS doesn't constitute a phenomenon. Other protective factor as a sympathetic aspects of motherhood they put their infants beside them at night watching them all night (hours) and dealing with them for any danger condition they watch. The cradle used in our countries (manual cradle) for beduins. Sleep prone was recommended from 1943-1988, although the first text to advice against front sleeping not published until 1992. The sleep position -On the back- was recommended sporadically during the 1980s, But not constantly until 1995 [54].

During my review all results or recommendations were contradicting each other, and no advised position by scientists was advised with certainty. Prone was recommended the prohibited, back was the same as risk factors, lateral positions the stated that it increases the risk of SIDS. So what is the harm and danger or safe by investigators the answer no answer. This is what the author answered it. Some statements of the investigators reveal uncertainty to all results or recommendations. Carolan stated: Supine or side sleeping position will not eliminate SIDS; infants have died in all sleep positions including back and side [29]. In fact this is true because early works concluded that putting infants to sleep prone decreased SIDS. Also it was a catastrophic recommendation of the American Academy of Pediatrics (AAP) when firstly issued the recommendation that infants be placed on their chestabdomen position (prone) until 1992 when they recommended that infants be placed on their back or side [55].

Alfleesy Hypothesis: The Right side sleeping position hypothesis: The author concludes that the current information, facts, and knowledge resulted in this study established the validity on which the hypothesis and suggested definition were based on:

\section{The author believes that}

1- All previous studies were unsatisfactory and lacking data that were mandatory if the hypotheses, theories, were to be validated.

2-The previous studies have not reached to a definite answer about the nature of SIDS in order to prevent it.

3- It is clear the absence of confirmed death mechanisms for SIDS, and uncertainty for determining its cause.

4- There is no single unifying theory to bring together the many observations that have been noted as factors in SIDS. 


\section{It has been shown by study that}

1) There is a lack of Criteria for both definition and diagnosis of SIDS.

2) There is consensus that sleep positions (mainly prone and supine) are associated with SIDS [1,2]. Some investigators said: lateral position between prone and supine [1].

3) There is increased resistance to airflow when an infant laid prone / supine to sleep $[49,56]$.

4) The prone/supine sleeping positions could be associated with lower arousal threshold [1].

5) It was proved that an arousal is a logical defense mechanism to protect breathing during sleep, the inability to arouse from sleep in response to hypoxia resulting in death [1].

6) The increased collapsibility in obstructive sleep apnea can be caused by an anatomical narrow pharynx, by an altered reflex response or changed neuromuscular control [49]. With a change of body position during sleep these factors may also change [49].

7) The lateral position can have a protective function by preventing the tongue from occluding the airway when the genioglossus muscle is hypnotic [49].

8) Obstruction of the upper airway-by the back of the large and muscular tongue falling posteriorly into the hollow of a soft yielding pharynx -in sleep- may obstruct the airway and even worsen as the baby inspires, thus enhancing negative pressure below the block [5,57].

9) Mechanical occlusion and upper airway obstruction are favored by supine / prone positions and increased airflow resistance [49].

10) Negative esophageal pressure is higher in supine / prone positions [57].

11) It is well known that hypoxia, stimulates the vagal inhibition [28].

\section{There is many known facts regarding the body structures, and from studies we found that}

1) Laying on Right side will ensure smooth breathing and lowering the resistance to breathing because the right bronchi remains in a good straight position and the short right lung will be in contact having a good right thoracic space. Hence the trachea will change its shape and length accordingly [1,49].

2) The liver in the right side of the body constitutes the base on which other organs lay down directly or indirectly in this position as it is the heaviest organ of the body.

3) Laying on right side position permits to establish a suitable direction to the stomach with its content of food that facilitates a smooth breathing.

4) The distention and pressure (mainly upward) by stomach - after ingesting food-upon the diaphragm well be decreased by this position.

5) The heart and left lung positioned in the upper side in the mediastinum gives the person an opportunity to breaths easily and gives the heart \& lung an opportunity to beat and move freely.

6) The clinical similarities between SIDS and ALTE are suggestive for their having the same risk factors, common causes, and mechanisms. All these similarities give a clue to the nature of SIDS.

\section{Final remarks}

1- Death occurs primarily by the process of mechanical obstructive asphyxia- resulting from some or all aforementioned factors. Taking every position on its own merits leading to hypoxia and death. It is not a sudden death but it is that cumulative and prolonged agony which might end suddenly to death in a critical period of time by stimulating vagal inhibition. The coincidence of timing suggests that infants are vulnerable to death during a critical period of time which followed the rule (all or none) if there is no interference in time.

2- There is no association between right side and SIDS found in this study and previous studies. This lack of association of SIDS and right side sleeping position is strengthened by many supporting observations. The culture, traditions and instructions of Islam all advise the right side sleeping position and breastfeeding. Allah says: "Mothers shall suckle their children two years completely for such as desire to fulfill the suckling" [52].

3- In the countryside of Yemen the habit of breastfeeding and right side sleeping position is the prevalence even in the Bedouins societies and tribes by using their Handols (manual cradles). Not only this, but our Sunna (the instruction of our Prophet Mohamed - BPUH) informed us that "the prone (front) position is prohibited and the right side position is advised to be the side of sleeping" [51,58]. Also in our religion the use of right is the prevalence in our Sunna.The author concludes that results suggesting a relationship between prone sleeping, non-breast feeding and SIDS, establish validity of the hypothesis that change to Rt. Sleeping will prevent the risk factors SIDS. 
So in an effort to solve this controversial problems the author wishes to put forward his right side sleeping position hypothesis to prevent SIDS as follow: If an infant be placed for sleeping on right side position after having breastfeeding then SIDS would be prevented.

The author concludes that clinical reports suggesting a relationship between prone sleeping and SIDS establish validity of the hypothesis that a change to Rt sleeping will prevent the risk of SIDS.

Right side position is a safe sleeping position for infants. The author believes that the mechanism of death is occurring mainly by mechanical obstructive asphyxia (hypoxia) which may end by stimulating vagal inhibition. The death is a process (a prolonged agony) which might end (suddenly), but it does not occur suddenly.

\section{Conclusion}

By this revision the author concluded the following:

1. It is striking that no studies were published on, in regard to right side sleeping position and no study gave the solution for SIDS.

2. The author suggested a new definition which is based on definite criteria in order to apply for diagnosis.

3. The author put forward his hypothesis for preventing SIDS, and determined the Right side position as the only safe position during sleeping.

4. This study explained the phenomena and disorders in concern as ALTE.

5. By all the results of this study, we feel that now it is possible for distinguishing SIDS, ALTE. By having the already mentioned criteria and characteristics.

Finally we could say Rt. Side should be given a serious consideration, because the primary goal of the current study is to call researchers to examine the effect of Rt-side sleeping position versus other positions mainly prone. To validate these findings and to whether Rt sleep position is a safe one or a risky one, you have to study this hypothesis. As this study provides an opportunity to test the link between Rt side sleep position and safety sleep with no death. To my knowledge, no effort has been made to test the right side sleep and to establish the Rt sleeping position as preferred sleep position.

\section{Recommendation}

The revision recommended that healthy infants be positioned on their right side position, rather than on other positions when being put-down a sleep. Breast feeding must be encouraged. Semisolid food and bottle feeding should be avoided [59].

\section{Acknowledgement}

Finally I would like to thank Edwin Mitchill, Professor of Child Health Research Department of Pediatrics, and University of Aukland, New Zealand, who sent me his scientific opinion about my study. He declared that no studies have reported on the difference between right and left side sleeping position, and stated: this is a testable hypothesis.

\section{References}

1. Keens TG (1996) Sudden infant death syndrome. Pediatric potpourri, state of the Art 1996 university, children's, Medical group, Maui, Hawai 181.

2. Schwartz PJ, Southall DP, Valdes-Dapena M (1988) The sudden infant death syndrome. Cardiac and respiratory mechanisms and interpretations. Ann N Y Acad Sci 533: 1-474.

3. Athanasakis E, Karavasiliadou S, Styliadis I (2011) The factors contributing to the risk of sudden infant death syndrome. Hippokratia 15: 127-31.

4. Matthews TJ, MacDorman MF, Thomas ME (2015) Infant mortality statistics from the 2013 period linked birth/infant death data set. 64: 1-30.

5. Valdes-Dapena M (1986) Sudden infant death syndrome. Morphology update for forensic pathologist-1985. Forensic Sci Int 30 : $177-86$.

6. Polson CJ, Gee DJ (1985) The essential of forensic medicine 4th ed 568-71.

7. Othman SHA (1993) New trends in asphyxia, Acta medicinae legalis et socialis 43.

8. Rintahaka PJ, Hirvonen J (1980) The epidemiology of SIDS in Finland in 1969-1980. Forensic Sci Int 30: 219-33.

9. Knight B (1987) Legal aspects of medical practice Churchill livingstone, $4^{\text {th }}$ ed.

10. Beckwith JB (2003) Defining the sudden infant death syndrome. Arch Pediatr Adolesc Med 157: 286-90.

11. Sawaguchi T, Sawaguchi A, Fujita T, Kobayashi M (1994) Statistical estimation of diagnostic accuracy of SIDS in Japan. ACTA MEDICINAE LEGALIS, XLIV: 296-8.

12. Shapiro GHA (1988) Forensic Medicine. A guide to principles $3^{\text {rd }}$ ed. Churchill London.

13. Goberman AM, Johnson S, Cannizzaro MS, Robb MP (2008) The effect of positioning on infant cries: Implications for sudden infant death syndrome. Int J Pediatric Otorhinolaryngol 72: 153-65.

14. Markestad T, Skadberg B, Hordvik E, Morild I, Irgens LM (1995) Sleeping position and sudden infant death syndrome (SIDS): effect on an intervention programme to avoid prone sleeping. Acta paediatr 84: 375-8.

15. Irgens LM, Markestad T, Baste V, Schreuder P, Skjaerven R, et al. (1995) Sleeping position and sudden infant death syndrome in Norway 1967-91. Arch Dis Child 72: 478-82.

16. Kaada B (1994) Why is there an increased Risk for sudden infant death in prone sleeping? Fear paralysis and atrial stretch reflexes implicated? Acta Paediatrica 83: 548-57. 
17. Hoffman HJ, Damus K, Hillman L, Krongrad E (1988) Risk factors for SIDS: results of the National Institute of child Health and Human Development SIDS cooperative Epidemiological study. Ann N Y Acad Sci 533: 13-30.

18. Henderson-Smart DJ, Ponsonby AL, Murphy E (1998) Reducing the risk of sudden infant death syndrome: a review of the scientific literature. J Paediatr child Health 34: 213-9.

19. Orr WC, Stahl ML, Duke J, McCaffree MA, Toubas P, et al. after 5th author (1985) Effect of sleep state and position on the incidence of central and obstructive apnea in infants. Pediatrics 75: 832-35.

20. Longman (1992) Dictionary of English with colour illustration. Longman group UK limited.

21. Goldwater PN (2003) Sudden infant death syndrome: a critical review of approaches to research. Arch Dis Child 88: 1095-100.

22. Gilbert RE, Wigfield RE, Fleming PJ, Berry PJ, Rudd PT (1995) Bottle feeding and the sudden infant death syndrome. BMJ 310: 88-90.

23. Cordner M, Willinger M (1995) The definition of the sudden infant death syndrome. symposium IV: SIDS A259.

24. Willinger M, James LS, Catz C (1991) Defining the sudden infant death syndrome (SIDS): Deliberations of an expert panel convened by the National institute of Child Health and Human Development. Pediatr Pathol 11: 677-84.

25. Steinschneider A, Weinstein SL, Diamond E (1982) The sudden infant death syndrome and apnea/obstruction during neonatal sleep and feeding. Pediatrics 70: 858-63.

26. American Academy of Pediatrics (2005) Task Force on Sudden Infant Death Syndrome, The changing concept of sudden infants death syndrome: diagnostic coding shifts, controversies regarding the sleeping environment, and new variables to consider in reducing risk. Pediatrics 116: 1245-5.

27. Sawaguchi T, et al. (1996) The necessity of the standardization regards the term 'sudden in sudden infant death syndrome. Intern Pathology 46: 598.

28. Knight B (1987) Legal Aspects of Medical Practice. $4^{\text {th }}$ ed.

29. Carolan PL, Fernbach KL (1994) SIDS and infant sleep positioning: what we know, what parents need to know? Topics in pediatrics 12 : $15-7$.

30. Krongrad ER, O’Neill (1986) Near miss sudden infant death syndrome episode? Pediatrics 77: 811-5.

31. Consensus statement (1987) National Institutes of Health Consensus Development Conference on infantile Apnea and Home Monitoring. Pediatrics 79: 292-9.

32. Hunt CE, Shannon DC (1992) Sudden infant death syndrome and sleeping position. pediatrics 90: 115-8.

33. Hoffman HJ, Damus K, Hillman L, Krongrad E (1988) Risk factors for SIDS. Results of the National institute of Health and Human Development SIDS Cooperative Epidemiologic Study. Ann N Y Acad Sci 533: 13-30.

34. Ponsonby AL, Dwyer T, Gibbons LE, Cochrane JA, Wang YG (1993) Factors potentiating the risk of sudden infant death syndrome associated with the prone Position. N Eng J Med 329: 377-82.

35. Mitchell EA, Thach BT, Thompson JMD, Williams S (1999) Changing infant's sleep position increases risk of sudden infant death syndrome. Arch Pediatr Adoesc Med 153: 1136-41.

36. Bergman A, Ray CG, Pomeroy MA, Wahl PW, Beckwith JB (1972) Studies of the sudden infant death syndrome in King County, Washington. III. Epidemiology Pediatrics 49: 860-70.

37. Hauck FR, Herman SM, Donovan M, Iyasu S, Merrick Moore C, et al. (2003) Sleep environment and the risk of sudden infant death syndrome in an urban population: the Chicago infant mortality study. Pediatrics 111: 1207-14.

38. Li DK, Petitti DB, Willinger M, McMahon R, Odouli R, et al. (2003) Infant sleeping position and the risk of sudden infant death syndrome in California, 19972000. Am J Epidemiol 157: 446-55.

39. Willinger M, Hoffman HJ, Wu KT, Hou JR, Kessler RC, et al. (1998) Factors associated with the transition to nonprone sleep positions of infants in the United States: the National Infant Sleep Position Study. JAMA 280: 329-35.

40. Kattwinkel J, Brooks J, Myerberg D (1996) Positioning and SIDS. AAP Task Force on Infant Positioning and SIDS. Pediatrics 98: $1216-8$.

41. MacDorman MF, Mathews TJ, Mohangoo AD, Zeitlin J (2014) International comparisons of infant mortality and related factors: United States and Europe, 2010 1-7.

42. Taylor JA, Krieger JW, Reay DT, Davis RL, Harruff R, et al. (1996) Prone sleep position and the sudden infant death syndrome in King County, Washington: a case-control study. J Pediatr 128: 626-30.

43. Beal S (1988) Sleeping position and sudden infant death syndrome. Med J Aust 149: 562.

44. Nicholl JP, O'Cathain A, Mcglashan ND (1988) Sleeping positions and SIDS. Lancet 2: 106.

45. Dwyer T, Ponsonby AL, Newman NM, Gibbons LE (1991) Prospective Cohort study of prone sleeping position and sudden infant death syndrome. Lancet 337: $1244-7$

46. Mitchell EA, Brunt JM, Everard C (1994) Reduction in Mortality from sudden infant death syndrome in new zealand: 1986-92. Arch Dis Child 70: 291-4.

47. Mitchell EA, Tuohy PG, Brunt JM, Thompson JM, Clements MS, et al. (1997) Risk factors for sudden infant death syndrome following prevention campaign in New Zealand: a prospective study. Pediatrics 100: 835-40.

48. Guilleminault C, Peraita R, Souquet M, Dement WC (1975) Apneas during sleep in infants: possible relationship with sudden infant death syndrome. Sci 190: $677-9$.

49. Penzel T, Möller M, Becker HF, Knaack L, Peter JH (2001) Effect of Sleep Position and sleep stage on the collapsibility of the upper Airways in Patients with sleep Apnea, Sleep 24: 90-5.

50. Wilcox E (1995) Hong Kong: supine tradition Holds Firm. BMJ 310: 10.

51. Zad Alma’ad Al-emam Al-hafed Ebi Abdulla ben Al-Ghozi (1972) 2 $2^{\text {nd }}$ ed. 1972 3-4: 143.

52. The Holly Qura'an, Surah The Cow Ayah No. 233.

53. Hauck FR, Kemp JS (1998) Bed sharing Promotes breastfeeding and AAP Task Force on Infant Positioning and SIDS. Pediatrics 102: 662-3.

54. Spiers PS, Guntheroth WG (1994) Recommendations to avoid the prone sleeping position and recent statistics for sudden infant death syndrome in the United States. Arch Pediatrics Adolesc Med 148: 141-6.

55. Orenstein SR, Mitchell AA, Ward SD (1993) Concerning the Academy of pediatrics Recommendation on sleep position for infants. Pediatrics 91: 497-9. 
56. Shatz A, Arensburg B, Hiss J, Ostfeld E (1996) Cervical posture and nasal breathing in infancy. Acta Anatomica 149: 141-5.

57. Skatvedt O, Grogaard J (1994) Infant sleeping position and inspiratory pressures in the upper airways and oesophagus. Arch Dis Child 71: 138-40.

58. Muhamed MK, Al-Bukhari S, Arabic-English. Hadith No. 247.

59. Ford RP, Taylor BJ, Mitchell EA, Enright SA, Stewart AW, et al. (1993) Breastfeeding and the risk of sudden infant death syndrome. Int J Epidemiol 22: 885-90.

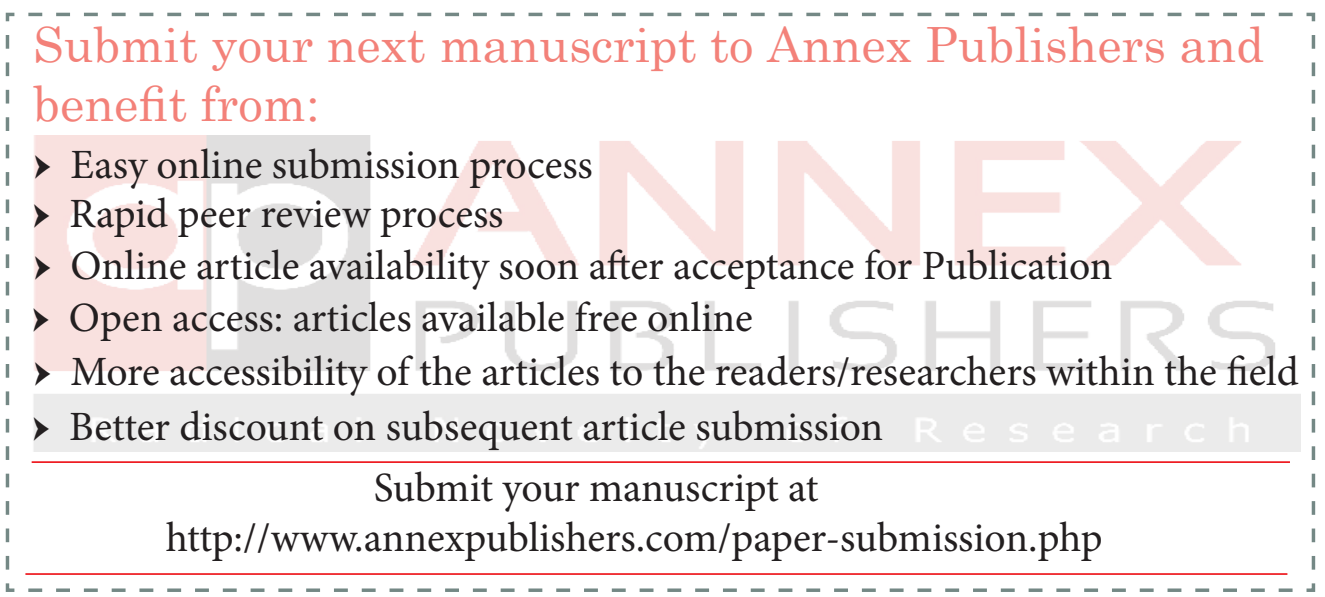

